\title{
PRESENTACIÓN DE LA SELECCIÓN DOCUMENTAL \\ DOCUMENTOS PARA EL PRESENTE: UNA MIRADA ARQUEOLÓGICA A LA MISIÓN DE LA UNIVERSIDAD DE CHILE
}

\section{Alejandra Araya Espinoza, Azun Candina Polomer}

La selección de documentos de este volumen fue ardua e interesante. No se presenta como una tarea terminada ni exhaustiva de todos los acervos y repositorios posibles de ser consultados, sino como una propuesta de lectura de las voces y miradas de aquellos que a lo largo del tiempo asumieron a la Universidad de Chile como parte de la construcción del Estado chileno y de un proyecto republicano que era el norte de la institución. Los textos e imágenes escogidos lo han sido porque se ha considerado que son parte de una historia colectiva y de larga data, entregada de generación en generación como parte de la constante defensa de la Universidad de Chile como garante del principio de la educación pública y sinónimo de Estado Docente. Es por esto que, como se señala en la introducción a este volumen, el énfasis está puesto en el rol fundamental que le cabe a la Universidad en la construcción de nuestro país, así como la importancia de preservar su misión y rol dentro del contexto actual en que la educación pública y el rol docente del Estado está en debate. Desde esta perspectiva, los documentos seleccionados pueden aportar a él desde dos ejes: las crisis del país como crisis de la Universidad y la Universidad de Chile y los desafíos nacionales.

La investigación mostró que la tarea de construir y defender la Universidad pública ha sido compartida por académicos, autoridades, funcionarios y estudiantes, que desde sus diferentes lugares de trabajo y estudio reflexionaron sobre lo realizado y propusieron los cambios y continuidades que su casa -como se ha destacado en esta introducciónnecesitaba. En gran parte los documentos presentados aquí corresponden a publicaciones hechas por la misma Universidad para dar cuenta de sus gestiones, como la emblemática revista Anales y las publicaciones especializadas editadas por las facultades, las declaraciones de centros de estudiantes, cartas de académicos, informes y cuentas de servicios, libros conmemorativos de los aniversarios de fundación, documentos de trabajo de circulación interna, folletines, boletines de comisiones e impresos informativos. Entre ellos, ocupan un lugar especial los discursos de sus rectores, no solo por ser las autoridades que representan a la corporación, sino porque la complejidad de la misma les exigía rendir cuenta en forma de síntesis de la labor realizada o, como señalan muchos, sobre "los trabajos de la Universidad", al mismo tiempo que informaban las proyecciones de la institución y sus desafíos, marcaban sus líneas de acción, denunciaban y hacían ver sus necesidades antes las autoridades del país y la sociedad en general en su calidad de interlocutores naturales.

La Universidad de Chile es una institución muy compleja tanto material como humanamente; a veces deja la impresión de que a lo largo de sus ciento setenta años de 
existencia no solo se ocupó del país, sino que salió a instalarse en él, a rodar por sus caminos e historias, recogiendo y quedándose al mismo tiempo. Ello comporta un desafío mayor: decidir qué documentos e imágenes seleccionar en tanto representativas de nuestra historia, pues ella se despliega de diversas formas en cada uno de sus organismos y también de sus miembros más permanentes y de lo que podríamos llamar la experiencia de estar en la Universidad. Es por esto que es interesante constatar que la unidad en dicha diversidad y heterogeneidad está dada justamente por intentar cumplir, por sobre todo, con la misión central que le fue dada por el mismo Estado chileno cual fue la de la instrucción pública nacional. Dicho mandato también se expresó y se expresa en una estructura compleja y variada, que la ha obligado a revisar permanentemente sus estatutos y su funcionamiento. Nos encontramos con la creación y reestructuración permanente de servicios centrales, facultades, departamentos, centros e institutos, y se debe destacar la autonomía que estos manejan para definir sus carreras, programas y actividades. Es por ello que nos pareció relevante incluir textos que reflexionan desde las transformaciones de las leyes que regulan el funcionamiento de la institución la que, desde esta perspectiva, replican el constitucionalismo que caracteriza a la historia política y social de nuestro país: todo cambio debe finalmente ser sancionado por una ley fundamental.

El cultivo de las disciplinas y el servicio al país aparecen en diferentes documentos y lenguajes como principios orientadores del quehacer de la Universidad. Sin embargo, estos imperativos no han sido fáciles de asumir y en ocasiones han sido paradojales: por una parte, la Universidad ha sido entendida como una institución eterna, custodia y guardián del patrimonio nacional y su saber y defensora de principios fundamentales, y al mismo tiempo se ha esperado que sea un centro dinámico, señero, vanguardista y pionero en los cambios que el país necesitaría, pues la Universidad fue identificada y se entendió a sí misma como el lugar desde donde esas necesidades nacionales podían ser diagnosticadas y asumidas, a partir de la formación de profesionales y técnicos y de sus labores de investigación y expansión de las fronteras del conocimiento. Se ha exigido que la casa tenga muchas puertas, pero que siguiera siendo la casa -la Casa de Belloque todos pudieran reconocer.

En la presente tarea, uno de nuestros hallazgos o tal vez confirmaciones fue que la Universidad de Chile, como muchas instituciones públicas, no cuenta con un archivo que organice y resguarde las huellas de su funcionamiento cotidiano. La disgregación espacial de la Universidad tiene su correlato en la información desagregada y dispersa de su vida académica, donde el registro de muchas actividades valiosas y dignas de recordarse queda a la voluntad o el interés personal de funcionarios, académicos o estudiantes que las rescatan del olvido. Pensemos en todos los registros que no califican como documentos oficiales que (en teoría) estarían resguardados y organizados: ¿qué pasa con los seminarios, conferencias, programas de cursos, registros de sus visitantes, discursos pronunciados en ceremonias diversas, currículos de los profesores, afiches, panfletos, grafitis, murales, grabaciones de actividades, fotografías de eventos y reuniones? Cuando decimos que los llamados documentos oficiales no están resguardados y organizados, no decimos ausencia de una organización, sino ausencia de una política de archivo que señale qué, cómo y dónde se debe guardar. Dicho proyecto archivístico 
debe ser pensado como una necesidad de memoria. Sin embargo, requiere de debate y decisiones, puesto que la gran variedad de "cosas que suceden" en la Universidad se entienden como la normalidad dentro de "un país en pequeño". Pensemos en que todas sus Facultades funcionan autónomamente y generan actividades y documentación día a día. Los distintos servicios poseen archivos o archivadores, hay bodegas en todas las dependencias copadas de documentos y objetos, oficinas de partes, secretarías, archivos de naturaleza específica, museos y sus respectivas documentaciones, y cada día se generan más y más registros. Y sabemos también que las transformaciones institucionales (aparición y desaparición de organismos) afecta la organización, regularidad y conservación de los documentos que permitirían reconstruir su funcionamiento, como también los avatares de la política nacional, las intervenciones, los despojos, los accidentes, las catástrofes, los descuidos y la ausencia de una conciencia patrimonial inciden -en toda institución- en los restos, huellas y vestigios de los cuales podemos disponer. Las memorias escritas de los miembros de esta institución se recogen en cierta forma en publicaciones igualmente dispersas en las bibliotecas de nuestra Universidad. Sin embargo, los relatos orales de los protagonistas de la segunda mitad del siglo XX requieren de una acción urgente que permita oír y registrar lo que tienen que contarnos y traspasar a la sociedad en su conjunto. Los archivos personales de profesores, académicos y funcionarios también requieren de, al menos, un proyecto de registro y catastro que nos permita saber dónde están y qué contienen. Cabe destacar en esta dirección, los esfuerzos permanentes que realizan dos de sus facultades fundadoras: la Facultad de Medicina y la Facultad de Ciencias Físicas y Matemáticas.

De cara a esta situación, cobra mucho valor la documentación producida conscientemente por la institución para verse y contarse a sí misma, como en el caso de las cuentas de los rectores y los libros conmemorativos. Las historias allí narradas son también parte del registro de la historia nacional, en la medida de que-como se muestra en esta selección y se explicará con más detalle en las secciones siguientes- los avatares de la Universidad de Chile fueron parte de los debates nacionales y también porque muy a menudo sus académicos fueron hombres -y luego mujeres- de lo público, que combinaban sus funciones docentes y de investigación con sus labores como senadores, ministros, diplomáticos, escritores, artistas y profesionales, pues el servicio público se concebía como un deber que cruzaba la formación de quien pasaba por las aulas de esta gran Casa llamada Universidad de Chile. En los documentos seleccionados, queremos mostrar a esos hombres de lo público que, siguiendo el ejemplo de Andrés Bello, asumieron diversas responsabilidades como un Samuel Lillo, funcionario universitario y escritor, Pedro Aguirre Cerda de estudiante a ministro de Instrucción Pública y de allí a presidente de la República y por tanto, patrono de la Casa que lo formó, o un Juvenal Hernández, el más joven de sus rectores, el conductor de la institución entre dos guerras mundiales, enfrentando crisis económicas que afectaban directamente las partidas universitarias, "padre" de la nueva Universidad a inicios del siglo y figura compleja en la aciaga década de 1970, cuando formó parte del Consejo de Estado de la Dictadura militar -y por qué no pensar en que desde allí quiso protegerla- y al morir recibió el homenaje de un Rector designado que vestía uniforme. 
Hablamos, debe reconocerse, más de hombres de lo público que de mujeres: a fines del siglo XIX se autoriza a las mujeres a ingresar a la Universidad y seguir carreras profesionales, pero no ocuparían los podios ni las cátedras universitarias sino décadas más tarde; Amanda Labarca en 1922 fue la primera mujer que se convirtió en académica de la Universidad, a 80 años de su fundación. De allí que haya muy pocas o prácticamente ninguna mujer que aparezca como autora en los textos y discursos que aquí se presentan, y que podamos encontrarlas particularmente en las imágenes: en los laboratorios, en las salas de clase, en las escuelas experimentales, en el deporte y también en las estadísticas para decirnos que son mayoría entre el estudiantado, tendencialmente, desde la década de 1940. No obstante lo dicho, es en la Universidad de Chile donde se dan estos hitos fundamentales en una historia de las transformaciones de las relaciones de género en nuestro país, expresada también en las investigaciones que sus profesionales y académicas realizan, así como en la instalación de estas demandas y propuestas en una institución que también ha sido la casa de las vanguardias, de las utopías y, por qué no decirlo, de los proyectos estratégicos.

Las fotografías que aquí se reproducen fueron producidas en su mayoría durante el rectorado de Juvenal Hernández (1933-1953) y de Juan Gómez Millas (1953-1963). En ellas vemos una Universidad que se proyecta a sí misma al futuro en el lente de destacados fotógrafos nacionales que hicieron su carrera en la propia institución, pues en ella pioneramente se desarrollaron las nuevas tecnologías que, como dirá el propio Juvenal Hernández -al reformar la Facultad de Bellas Artes- pusieron en jaque a los artistas de formación clásica frente al cine sonoro y las grabaciones magnéticas. Los laboratorios de cinematografía educativa, de ensayes eléctricos y de materiales y las nuevas construcciones universitarias, se miran desde la estética de la nueva fotografía, mientras que la fotografía social impregna el discurso de los proyectos asociados a los desafíos pedagógicos, la infancia y la salud pública.

Muchos de estos documentos operan como lugares de memoria, como vestigios y huellas de un instante o de una fractura dramática en el funcionamiento cotidiano y normal de la Universidad de Chile. Por ejemplo, el primer correo electrónico representa aquí el trabajo "silencioso" de la ciencia y la tecnología, si se compara con los objetos y procedimientos de humanistas y cientistas sociales para los cuales la palabra y el registro de ella son fundamentales, para quienes público también es publicar o ser en público y frente a un público. Mientras que los desafíos nacionales fueron para esta investigación también un desafío documental al igual que la dolorosa fractura que representa la intervención militar de la Universidad tras el Golpe de Estado de 1973. Allí también se fractura la conformación de los archivos; es posible, por omisión y por eufemismo, escuchar el desgarro de la repartición muda, triste y sin posibilidad de reclamo público de una Universidad que fue despojada de sus sedes regionales y del Instituto Pedagógico, donde se cierran carreras, se exonera a académicos y funcionarios, donde se empieza a contar a los detenidos desaparecidos y los ejecutados políticos que eran parte de nosotros y donde la comunidad universitaria se fractura profundamente pues la desconfianza, el aislamiento y el miedo acallan a una voz que interpelaba al Estado y la sociedad permanentemente como corporación. 
Traspasada por las grandes transformaciones que implanta la Dictadura Militar, la Universidad de Chile debe enfrentar nuevos escenarios. El cierre del Salón de Honor, por su último rector elegido, Edgardo Boeninger -que deja en libertad de acción a sus académicos frente a la inevitable intervención- sella ese silencio fúnebre cuando su mano cierra por fuera la puerta de dicho salón. Este permanece clausurado a la comunidad cuando se conmemora un nuevo aniversario en noviembre de 1974 y se abre para recibir al General Augusto Pinochet Ugarte como su nuevo Patrono en el inicio del año académico de 1975.

Los documentos que seleccionamos para este período son tachaduras, reescrituras de un discurso institucional, de las apropiaciones y de las recuperaciones, de los pasos complejos de un cuerpo dañado, con síndrome de miembros fantasmas y con traumas que aún impiden la construcción de un relato y de un proyecto que recupere el habla de una comunidad y de una institución. Son marcas, son cicatrices, son el inicio de un reconocimiento, son jirones de piel, son culpas, son orgullos, son la Universidad de Chile que cierra el siglo XX en las primeras décadas del siglo XXI.

\section{PRIMERA PARTE: CRISIS DEL PAÍS, CRISIS DE LA UNIVERSIDAD DE CHILE}

Desde las discusiones sobre su creación, la Universidad de Chile fue parte de un proyecto republicano, en la medida que Chile -esa apuesta lanzada sobre la mesa de un imperio que se derrumbaba- quería constituirse y ser reconocido como una nación moderna en el concierto de las naciones, y para ello debía generar instituciones propias cuya tarea sería encarnar esos ideales. La revisión de los debates parlamentarios y los discursos de la primera mitad del siglo XIX que explican la fundación de la Universidad, dejan claro que no se buscaba solamente crear una institución que reemplazara a la educación superior impartida durante el período colonial. La creación de la Biblioteca Nacional (1811), luego del Instituto Nacional (1813) y finalmente la decisión de crear una nueva casa de estudios superiores, fueron parte de ese proyecto fundacional republicano con fe en un futuro propio y en su continuidad.

Esto significó para la Universidad haber nacido con el apoyo del Estado en la tarea de cumplir sus objetivos y funciones, pero también haber estado directamente involucrada en los debates, crisis y cambios de timón de la política nacional. Lo que ha ocurrido y le ha ocurrido a Chile en términos de conflictos sociales, asonadas políticas, reformas, revoluciones, avances y retrocesos en su desarrollo, también le ha ocurrido a la Universidad de Chile, y no solamente como una caja de resonancia de los problemas y debates nacionales, sino muchas veces como uno de los lugares donde esos conflictos tuvieron lugar y también afectaron, para bien y para mal, a la vida universitaria. La Universidad de Chile fue vista por distintos gobiernos y grupos a menudo como una oportunidad y en otras ocasiones como una amenaza frente a proyectos específicos de sociedad.

A fines del siglo XIX y particularmente en las primeras décadas del siglo XX, la Universidad de Chile fue uno de los espacios donde se discutieron las carencias y la crisis del Estado decimonónico. Los intelectuales de la naciente clase media profesional 
y los estudiantes encontraron un lugar donde expresar su descontento y debatir las nuevas ideologías que a nivel mundial buscaban la transformación social y que también cambiaron la política y la sociedad chilenas. La creación de la Federación de Estudiantes de Chile (FECH) y de su conocida y ya clásica revista Claridad da cuenta de ello. Asimismo, en 1927 el Gobierno de Carlos Ibáñez del Campo anunció que usaría sus facultades extraordinarias para dar a la Universidad de Chile una nueva organización, a lo cual tanto su rector Claudio Matte como el Consejo Universitario se opusieron por considerarlo una intervención indebida en los asuntos universitarios, y presentaron su renuncia. Paralelamente, la revuelta estudiantil en contra del general Ibáñez culminó en una huelga general que terminó con su renuncia al poder, como también quedó presente en la memoria de los estudiantes de la época y marcó los discursos de los rectores de allí en adelante.

De tal manera, la discusión sobre los nuevos estatutos universitarios de 1931 no fue un proceso académico aislado, sino que estuvo profundamente relacionado con uno de los puntos de inflexión de la historia de Chile contemporáneo y de la historia de la Universidad de Chile. La casa de estudios no estuvo ajena a la fuerte crisis política en el país, los cuestionamientos al régimen liberal parlamentario y las propuestas por un rol más activo del Estado en la educación y su reorganización y ordenamiento en la primera mitad del siglo XX. Los debates al interior de la Universidad y el impulso transformador de la sociedad que buscaba un mayor y más claro apoyo del Estado en los asuntos de interés público se cristalizaron en el nuevo estatuto orgánico, que buscaba consolidar el rol científico y profesional de la Universidad y el aumento de su influencia en la cultura general del país, y que aseguró su autonomía del Poder Ejecutivo. Fue durante el rectorado de Juvenal Hernández -elegido en dicho cargo Rector apenas frisando los 30 años de edad-donde la casa de estudios asumió con particular fuerza su rol académico en la modernización que el país necesitaba en términos de investigación y formación de profesionales en las áreas de las ciencias, las artes y las humanidades, y donde se inició el camino a una Universidad particularmente abierta a la extensión y los contactos internacionales, a partir de la creación de institutos, laboratorios, seminarios y bibliotecas. Puede decirse, en resumidos términos, que durante los rectorados de Juvenal Hernández y Juan Gómez Millas la Universidad vivió su período de mayor expansión en términos de matrícula universitaria y creación de nuevas sedes, facultades e institutos. A un siglo de su fundación, estaba instalada como el mayor centro formativo y de investigación del país y cumplía plenamente con la definición de una Universidad pública y estatal, o como se señala en los textos: la Universidad Nacional.

Sin embargo, el mismo desarrollo del país en la segunda mitad del siglo XX y las numerosas tareas pendientes que nuestro algo frágil Estado de Bienestar dejaba sin hacer, y un contexto internacional de crítica y rebeldía a la cultura y los modelos políticos dominantes, hicieron de la década de 1960 otra década de crisis y esperanzas, la cual también estuvo presente e influyó en la vida universitaria. El sentido de inminencia y a veces casi de inevitabilidad de los cambios que caracterizó a la década, la percepción de que había que estar allí y que ni la sociedad ni el mundo universitario podían ignorar ese contexto fue, particularmente, fuerte en la Universidad de Chile. Era necesaria una 
reforma profunda a las estructuras y la orgánica de poder universitaria, y esta debía realizarse sin dilaciones.

Según los testimonios y textos existentes, esta reforma tuvo en líneas gruesas dos grandes objetivos. El primero fue la transformación interna de la Universidad, demandando reformas administrativas que estimularan la investigación y su vínculo con la docencia universitaria, especialmente a partir de la instauración de nuevos concursos para contratar académicos y la creación de nuevos departamentos o la transformación de los anteriores, con miras a una mayor integración de la Universidad a la solución de los problemas sociales y políticos de Chile, donde hubo iniciativas de estudiantes y académicos desde comienzos de los años 60. El segundo objetivo fue la democratización interna de la Universidad, demanda que no estuvo ajena a los reclamos por mayor participación y democratización que se vivían en el país en su conjunto. Se produjo un fuerte y profundo debate con respecto a la participación de los distintos estamentos en la elección de los cargos y autoridades y en el diseño de las políticas universitarias, que tenía como centro el rol de la Universidad en el fuerte proceso de transformación estructural que estaba viviendo el país. Los discursos de los rectores y decanos de la época, los testimonios de los entonces estudiantes y los programas de las elecciones a rectoría finalmente cristalizaron en el nuevo estatuto de 1971, que consagraba una vez más la misión pública de la Universidad, esta vez con mayor participación de los estamentos en las decisiones internas y también con una postura más claramente social y crítica hacia el exterior.

El futuro de dicha reforma universitaria y qué habría significado para la Universidad y el país del último tercio del siglo XX quedó como una pregunta truncada por el golpe de Estado de 1973. Sin embargo, los avances que se lograron en términos de democratización y su conexión con el arte, la política y el pensamiento crítico chileno e internacional quizás ayuden a comprender por qué la Universidad fue tan directa y claramente violentada por el nuevo Gobierno de facto. La institución de los "rectores delegados", el cierre de carreras, institutos y centros, la exoneración de cientos de funcionarios y académicos, la persecución por la policía política del régimen de los "sospechosos" en los mismos patios y aulas de la Universidad dan cuenta de una operación de limpieza -en aras de recuperar la "vida académica"- que prueba mejor que cualquier argumento a posteriori la peligrosidad de la Universidad como centro de pensamiento crítico y debate abierto. La casa universitaria se convirtió en una casa tomada y amordazada, y según los testimonios y documentos del período, se instaló un ambiente de temor, desconfianza mutua y aislamiento que ha dejado sus huellas hasta hoy.

En un proceso que aún no está investigado y expuesto sistemáticamente y del cual presentamos aquí solamente retazos; también, a fines de la década de 1970 se dio inició a un profundo proceso de pérdida de financiamiento por parte del Estado y de jibarización de la Universidad, revirtiendo la expansión que se había vivido desde comienzos del siglo XX. 1981 fue un año clave al respecto, y probablemente no es casual que numerosas medidas se hayan tomado luego de ser aprobada la nueva Constitución de la República en 1980 y de que la Dictadura viviera uno de sus momentos de mayor estabilidad y poder político. En 1981 se decretó un nuevo estatuto universitario que fue enviado directamente desde el ministerio de Educación a la casa de estudios y del cual 
publicamos la nota que acompañó al proyecto, y se decretó también la separación del Instituto Pedagógico fundado en 1889 de la Universidad de Chile y de las sedes regionales de la Universidad. Asimismo, el aporte fiscal sufrió recortes severos, en un proceso cuyo objetivo era el autofinanciamiento y la privatización de la educación superior y la investigación, cuyas consecuencias también se viven hasta hoy.

Los discursos de los rectores delegados y otros documentos aquí compilados, no son de forma alguna la historia de la Universidad en Dictadura, pues dicha empresa, esperamos, deberá iniciarse con estos volúmenes especiales. Sin embargo, muestran para muchos por primera vez la violencia a la que fueron sometidos los símbolos republicanos y democráticos que nuestra Casa de Estudios representa y defiende. Leer discursos de 1975 o 1977 que apelan a estos valores en la figura de un Rector militar, invocando a filósofos de la antigüedad y humanistas en tanto el miedo, la delación, la tortura, el exilio y el hostigamiento interno imperaban en la "comunidad" universitaria, no puede sino producir escalofríos. Y también debe impulsar nuestras reflexiones y la profundización de una memoria que permita hacer los duelos, redimir las culpas y abrir nuevos caminos sin olvidos entre los que no están, los que se quedaron, los que sobrevivieron y los que apoyaron.

Frente a la amenaza de la virtual desaparición de la Universidad pública y el autoritarismo instalado en la política y la sociedad chilenas, el mundo universitario comenzó en un adverso contexto a organizar su respuesta. En un tono más respetuoso y técnico o más abiertamente confrontacional, tanto los académicos como los estudiantes empezaron a hacer llegar al Gobierno su protesta; los decanos se declararon en contra del proceso de regionalización de la Universidad en el mismo año 1981. Ya antes de la crisis y recesión económica de 1983, y que haría masiva la protesta social contra el Gobierno de facto, desde fines de la década de 1970 nuevas organizaciones estudiantiles como la Agrupación Cultural Universitaria (ACU) y la reorganización de la histórica Federación de Estudiantes (FECH) dieron cuenta de los antecedentes del proceso de movilización en la Universidad.

Desde 1983, y en adelante, nuevamente nos encontramos con una Universidad donde el debate tanto por la defensa de su propia identidad e intereses como por los del país encontró un lugar. Los estudiantes de la FECH denunciaron directamente ante las autoridades el alza de los aranceles universitarios y la represión y censura al interior de la Universidad y plantearon sus actividades no solamente como un reclamo interno, sino como parte de la defensa de la libertad de expresión y acción de los estudiantes y el país en su conjunto, como puede verse en los documentos del Archivo FECH aquí reunidos. Asimismo, la creación de la Asociación de Académicos y del Claustro de Profesores Titulares (1986) fue significativa, en la medida que crearon una instancia de reunión para pronunciarse ante la merma de recursos y la situación represiva al interior de la Universidad, pero también por las condiciones generales del conjunto de las universidades y del país. En ese contexto, debe mencionarse en particular el gran movimiento de rechazo a la rectoría de Juan Luis Federici (1987), donde una organización transversal de decanos, académicos, funcionarios y estudiantes se opuso a las llamadas políticas de "racionalización" de la Universidad. Tras una larga y compleja lucha se logró 
la salida del rector delegado, a pesar de los esfuerzos de dicha persona -apoyada por el Gobierno- para rechazar el movimiento, a partir, por ejemplo, de la exoneración de académicos involucrados, como en el documento original presentado en estas páginas, medida que finalmente no se concretó pues debía cumplirse con el trámite de ser notificada tal medida a la Contraloría General de la República, cuestión que no se llevó a cabo por esas "cosas de la historia", pero que sin embargo tuvo hondo impacto al ser leída en un comunicado transmitido por la Radio Cooperativa a las cuatro de la tarde del día 17 de septiembre de 1987, a 144 años de la ceremonia de instalación de la Universidad de Chile y del memorable y emblemático discurso de su primer rector.

En 1990, Chile se enfrentaba al desafío de reiniciar un camino democrático luego de 17 años de dictadura militar que habían cambiado profundamente la vida nacional. Las heridas y las tareas pendientes eran múltiples, y también lo fueron en la Universidad de Chile. Según los testimonios de quienes estuvieron y participaron en ese proceso, la fragmentación y falta de comunicación entre los distintos campus y facultades universitarias era grave. Había que reiniciar los procesos democráticos dentro de la Universidad y reconocer y tratar la situación de quienes habían sido exonerados por motivos políticos de la institución, todo ello en el contexto de recuperar el rol de la educación pública en el país.

Solamente parte de dicha tarea se ha cumplido. A comienzos de la década de 1990 se eligió al primer rector en democracia, el Doctor Jaime Lavados, a través de un mecanismo de consulta creado para la situación de excepción, que a lo largo de los años se convirtió en un proyecto de nuevo estatuto universitario que fue completado en la rectoría del profesor Luis Riveros y que finalmente fue aprobado mediante una consulta a todos los estamentos y entró en vigencia en el año 2006, luego de un proceso de siete años de trabajo en la misma Universidad. Así se establecieron hasta hoy los mecanismos de elección de directores, decanos y rectores, e involucrando la creación del Senado Universitario y la participación formal de estudiantes y funcionarios en dicha instancia y en el Consejo Universitario y los Consejos de Facultad.

Asimismo, se inició la larga y difícil tarea de reincorporar a quienes habían sido apartados injustamente de la Universidad, solo parcialmente cumplida hasta hoy por las dificultades propias del paso del tiempo y de las posiciones disponibles en las diferentes facultades y servicios y la falta de apoyo gubernamental. Presentamos aquí, como documentos originales, algunos de los diplomas entregados de manera póstuma a los estudiantes que perdieron la vida en Dictadura y quienes la Universidad reconoció como especiales miembros. Muchas de estas propuestas y ceremonias se llevaron a cabo en la Casa Central -aunque también en sus facultades-y los registros visuales y testimoniales de ellas no están localizados ni reunidos, suponemos que en algunos hogares y oficinas, y en las memorias ellos sí estén y puedan ser compilados algún día. Las historias de nuestra Casa, en las complejas relaciones cotidianas y domésticas de la Dictadura y la Transición Democrática, todavía no se cuentan lo suficiente y lo necesario.

En una tarea de más largo aliento, y que se encuentra abierta hasta el día de hoy, se inició también la demanda por exigir al Estado la recuperación de la Universidad pública en términos del financiamiento y apoyo a sus labores. En dicho sentido han existido 
avances parciales pero una situación crítica en términos generales, donde los reclamos y demandas universitarios no han sido tomados en cuenta de manera cabal, como puede verse en los documentos presentados en estas páginas que abarcan desde la década de 1990 hasta la actualidad. Tanto las federaciones estudiantiles como las autoridades universitarias han hecho presente una y otra vez a los gobiernos democráticos la urgencia de esa necesidad, y presentamos aquí los documentos refundacionales de la FECH en democracia y también del Nuevo Trato buscado por las autoridades universitarias.

En dicho sentido, el conflicto entre una visión neoliberal de la sociedad y la política y una de mayor responsabilidad estatal en los servicios y derechos básicos de la población que ha atravesado el país en los últimos 20 años también ha estado presente en la vida universitaria. La tensión sigue presente y sigue teniendo características dramáticas: no es una casualidad que en la Universidad se haya acuñado el término de la "vocación pública" y no solamente "Universidad pública", como una manera de expresar que si bien el objetivo de ser parte activa de los desafíos nacionales sigue presente, actualmente es más un imperativo moral y ético que una realidad presupuestaria, dados los magros y parciales aportes del Estado a la educación superior que fue su creación. Sin embargo, y partir de allí, los discursos, debates y documentos aún no están aquí consignados, porque nos toca a nosotros construirlos.

\section{SEGUNDA PARTE: UNIVERSIDAD DE CHILE Y DESAFÍOS NACIONALES}

Desde su creación la Universidad de Chile fue pensada como la Universidad Nacional, de allí la adopción del nombre del país para referirse a ella. Esta dimensión está declarada en todos los documentos del siglo XIX y XX que hemos revisado y en gran parte de la selección reunida en la primera parte de este volumen. En el proyecto de ley para el establecimiento y organización de la Universidad de Nacional de julio de 1842 (seleccionado en la Primera Parte), podemos leer que las funciones y misión de cada una de sus facultades son en realidad proyectos para la construcción del Estado Nacional, el primer gran desafío luego del llamado período de los ensayos constitucionales y de la primera organización de la República que culminó en 1830.

En esa segunda etapa republicana que marcó gran parte del siglo XIX, la Facultad de Filosofía y Humanidades debía hacerse cargo de la dirección de las escuelas primarias, la redacción, traducción y revisión de los textos que se utilizarían en ellas y promover el estudio de las humanidades especialmente a la "lengua, literatura nacional, historia i estadística de Chile". La Facultad de Ciencias Físicas y Matemáticas, junto con promover los ramos que le eran propios, debía poner particular atención en la construcción de todos los edificios y obras públicas. De igual forma, la Facultad de Medicina tendría el deber de estudiar las enfermedades endémicas de Chile, las epidemias más frecuentes de las "ciudades y campos del territorio chileno" y dirigir sus investigaciones a la mejora de la higiene y salud pública. Su decano, además, era investido como el "Proto-médico del Estado", es decir, su Ministro de Salud, sin existir ese ministerio aún. La Facultad de Leyes y Ciencias Políticas sumaba a su función académica el redactar y revisar los trabajos 
que le encargase el Supremo Gobierno. Incluso la Facultad de Teología debía tener disposición para poner cuidado a los trabajos relacionados con las Ciencias Sagradas que el gobierno le encomendase. Este mandato puede verse en las reorganizaciones, alianzas internas y modificaciones estructurales de la propia institución para poder cumplirlo; valga como ejemplo en el siglo XX la creación de los centros e institutos como el Centro Científico de la Vivienda (1953) que involucraba a las facultades de Ciencias Físicas y Matemáticas y Arquitectura, los Colegios Profesionales del ramo, la Corporación de Fomento, las Cajas de Previsión y el Servicio Nacional de Salud, muchas empresas particulares y semifiscales para resolver el problema de la habitación popular. Esta iniciativa estaba liderada, como muchas otras, por el Instituto de Investigaciones y Ensayes de Materiales (actual IDIEM).

En la primera mitad del siglo XX, la propia redefinición y debate permanente en torno a lo que significaba servir a lo público, así como la defensa de su calidad de la Universidad del Estado y de Chile, instaló los trabajos de la Universidad en todos los ámbitos de las políticas públicas y como organismo responsable o como garante natural de la implementación de dichas políticas desde su formulación a su puesta en práctica. La experiencia que le otorgaba la orientación de sus funciones, por mandato del propio Estado, la hacía la institución más idónea para asumir estos desafíos. En los años de 1953 y 1954 encontramos un hito importante en la disputa de tan estrecha relación natural entre las dos instituciones -Universidad y Estado- cuando la Pontifica Universidad Católica y la Universidad de Concepción presentaron al Ministerio de Educación peticiones para que se les reconocieran sus títulos como válidos, sin supervisión ni examen por parte de la Universidad de Chile, socavando -como escribía el abogado Raymundo del Río en uno de los documentos seleccionados- el principio del Estado Docente consagrado por la Constitución política del Estado y celosamente resguardado por las leyes universitarias por más de un siglo.

La disputa no fue menor, pues inicia el fin del rol de Superintendencia de Educación que había tenido la Universidad hasta entonces, lo que desde una lectura en perspectiva se puede entender como el fin de su papel fiscalizador de la instrucción pública, como brazo del Estado en dicha materia, como institución certificadora de la calidad de formación de los profesionales que el país necesitaba y, finalmente, el socavamiento de su rol dentro de la institucionalidad cultural del país. No se olvide que es el propio Estado el que, reconociendo dicha función, le había traspasado la Dirección de Cultura y otros organismos de difusión a la Universidad de Chile en el año 1948.

La selección de hitos y documentos que presentamos en esta segunda parte busca abordar esta relación, función y misión en proyectos específicos que ejemplifican dicha situación, sin ser la totalidad de iniciativas que estamos seguras la Universidad emprendió en los más variados campos de su quehacer y cuyo registro no siempre existe documentalmente. Pero este ámbito documenta en sí mismo la fractura en la relación del vínculo de nuestra Universidad con el Estado, pues desde fines de la década de 1970 -de forma coherente con el discurso de la "recuperación" de la Universidad para su función fundamental que era formar e investigar en silencio- desaparecen los proyectos relacionados con las políticas públicas e importantes instituciones. A modo de ejemplo, 
el INTA en el campo de la salud pública y el Observatorio Astronómico en la ciencia ya no fueron considerados ni consultados en sus ámbitos de competencia ni proyectos relevantes que otrora habrían sido parte de sus "trabajos" evidentes y "naturales". Así lo señalan los documentos que aquí presentamos. Es por esto también -y por eso decimos que los propios hitos son el documento- que no contamos con mayor información respeto de proyectos relacionados con desafíos nacionales desde fines de la década de 1980 hasta hoy. Se hace hegemónica una interpretación de la Educación como una labor preferente del Estado, como el deber de garantizarla por medio de una estructura de educación superior que no distingue entre universidades públicas, tradicionales y privadas; y nadie habla de una Universidad Nacional como sinónimo de Universidad de Chile. Dentro de dicha línea se insertan las medidas que fomentaron y favorecieron el florecimiento de las universidades privadas y la lógica de asignación de fondos públicos concursables para los llamados "temas-país". En un escenario totalmente diferente al del período pre-Golpe de 1973 y configurado por las leyes de excepción y, en particular, para la Universidad desde 1981 con el nuevo estatuto que la sitúa como una institución de educación superior dentro del concierto de las otras existentes.

Uno de los problemas que hoy se nos plantea en este escenario, que ya no es nuevo y que pretende convertirse en estructural, es el de la relación entre la investigación y los derechos de propiedad sobre ella. Para esta investigación, concretamente, fue evidente el problema cuando al preguntarnos por un posible catastro de los aportes de la Universidad en estos ámbitos, tanto en la dimensión de los "encargos" por parte del Estado -hoy más bien por un discurso que circula en público- como en la de las propuestas pioneras o emergentes por parte de la Universidad al país, constatamos varias cuestiones complejas. El estatuto de 1931 definió los centros e institutos como las instancias que permiten desarrollar investigación de punta con fines puntuales o en forma pura. Algunas de esas experiencias perduran hasta hoy, otras no sabemos si lograron concretarse más allá de su decreto de creación, como numerosos centros de estudios internacionales - estudios eslavos, por ejemplo, o el centro de estudios araucanos- de cuyo funcionamiento posterior no hay evidencias. En el listado de centros que se pueden catastrar en la actualidad, tenemos una amplia gama de tipos, fines y funciones, incluyendo centros creados a partir de financiamientos proporcionados por fondos públicos concursables. ¿Es posible decir que dichos espacios retoman la función que la Universidad tenía respecto de la configuración de las políticas públicas o de la formación del capital humano para enfrentar los desafíos nacionales o de su rol como institucionalidad cultural? Quizás uno de los cambios más profundos que se han producido en los últimos 40 años es el de quitar al Estado, más allá de su reducción, su condición de actor despojándolo de sus brazos institucionales, entre ellos la Universidad Nacional, que le permitía ejecutar y llevar a cabo dichas políticas. No se trata por tanto, solo de denunciar que hoy no existe claridad respecto de las políticas públicas, sino que preguntarse en qué tipo de instituciones se piensa para llevarlas a cabo, quién se hace responsable de ellas en el largo plazo, pues como están las cosas, caducarán en las fechas en que caducan las licitaciones.

La Universidad jugó y juega hasta hoy un papel pionero en desarrollos tecnológicos y científicos que a veces solo con el transcurso del tiempo han relevado su importan- 
cia para el desarrollo nacional en términos académicos y también de mercado. Dentro de esa área, este número especial de Anales ha querido destacar la contribución de la Universidad de Chile a enfrentar desafíos nacionales relacionados con las condiciones específicas de nuestra sociedad y de su territorio. En un país sísmico, debe mencionarse en particular y la creación del Servicio de Observaciones Sismológicas ya en 1906 -es decir, en el año del gran terremoto que destruyó buena parte del plan de Valparaíso-y el trabajo sostenido del ya mencionado IDIEM (Centro de Investigación, Desarrollo e Innovación de Estructuras y Materiales), fundado en 1898 como Taller de Resistencia y Ensaye de Materiales destinado a cumplir labores docentes, en particular a la carrera de ingeniería civil de la época y al Ministerio de Obras Públicas, y que sigue desarrollando hasta hoy tareas de docencia, investigación y asesoría tecnológica.

Para destacar esa labor pionera incluimos aquí documentos que muestran el interés de la Universidad en áreas como la informática en sus etapas tempranas: el primer computador llegado a Chile con fines docentes se instaló en nuestra Universidad en la década de 1950 y se produjo el software BIRDS que fue utilizado internacionalmente, y también destacamos que el primer correo electrónico enviado desde Chile, que fue remitido en 1985 como iniciativa de nuestra Universidad. Sumándose a lo anterior, se han incluido también los relatos sobre la creación del Laboratorio de Física Nuclear, en 1954, y del Labotatorio de Montemar en la década de 1930. Como mencionamos en el capítulo anterior, estas fundaciones dan cuenta del nuevo apoyo dado por el Estado a las labores universitarias tras la aprobación del nuevo estatuto de 1931.

Hacerse cargo y velar por el desarrollo y la calidad de la educación en Chile fue también una de las más importantes tareas universitarias durante el siglo XX. No se trató solamente de formar y titular maestros, sino de unir la docencia a la investigación, de mantenerse al tanto de las teorías y procedimientos didácticos a nivel internacional. Un hito en particular fue la creación del Instituto Pedagógico en 1889, que buscó organizar y modernizar la enseñanza para profesores en Chile y también convertirse en un centro de investigación y producción intelectual de gran influencia en la construcción de los planes y programas de estudio de la educación primaria y secundaria, conectado a su vez con los avances internacionales en la materia, como bien se resume en los discursos del centenario de 1943. Asimismo, la extensión universitaria fue una de las tareas centrales del siglo XX: presente desde comienzos del siglo XX, se consolidó con las escuelas de temporada, tenían por objetivo abrir las puertas de la Universidad a los ciudadanos del país y los extranjeros.

De tal manera, y a lo largo del siglo XX, la Universidad se hizo cargo o creó espacios dedicados no solo al cultivo y la presentación de las artes, sino también de las nuevas tecnologías de comunicación como la radio y la televisión, buscando con ello tener una influencia en la cultura nacional. Se crearon el teatro Universidad de Chile, la Sala Isidora Zegers, la Radio Universidad de Chile, el teatro universitario, el centro de cine experimental que funcionó hasta 1973 y el liceo experimental artístico, que han sido durante el siglo XX espacios centrales en la presentación del arte docto y reconocido y también de las nuevas tendencias fuera y dentro del país. Igualmente se deben destacar los museos relacionados o dependientes de la Universidad de Chile, como el Museo de 
Arte Contemporáneo (MAC) en el Palacio de Bellas Artes, el espacio MAC en Quinta Normal, el Museo de la Medicina Profesor Enrique Laval y los Museos de Historia de la Farmacia y el Museo Nacional de Odontología. Prueba del reconocimiento internacional de la Universidad es el Museo de Arte Popular Americano Tomás Lago: con el motivo del primer centenario de la Universidad de Chile (1942), varios gobiernos americanos enviaron muestras de artesanía popular características de sus países las cuales fueron recibidas en calidad de donaciones. En 1943 el Consejo Universitario creó el Museo de Arte Popular Americano a partir de las donaciones, y el Museo fue inaugurado en 1944. Es por ello también que hemos incluido aquí documentos relacionados con el gesto de donar bienes a la Universidad por parte de diversas personalidades, incluyendo a los propios fundadores en dicho gesto confirman el voto de confianza a la institución en el resguardo y difusión de diferentes disciplinas por sobre cualquier diferencia ideológica, confesional o de otra naturaleza dogmática que pueda existir entre ellos. Desde un Gabriel Ocampo hasta un Pablo Neruda.

El trabajo editorial y de publicación de la Universidad no se ha olvidado, pero dar cuenta de dichos trabajos y organizar la información es, como en otros tantos temas, un proyecto con vida propia. No solamente fueron un canal de difusión para las investigaciones y reflexiones de los académicos de la Universidad; permitieron publicar y difundir textos clásicos de las humanidades y las ciencias, cuerpos documentales, ensayos, iconografía, traducciones y obras de nuevos autores dentro y fuera del ámbito universitario que colaboraron significativamente a la circulación del conocimiento y su debate en Chile. Dicha historia rebasa la labor, importante, por cierto, que realizan la Editorial Jurídica y la Editorial Universitaria, pues ello supone hacer el catastro de las publicaciones históricas, de las prensas en los espacios universitarios, de las políticas editoriales, entre muchas otras posibilidades.

Las líneas temáticas en que hemos dividido la selección pretenden más orientar una lectura que diseccionar las actividades de una Universidad que, esperamos quede aquí expuesto, cumple su misión de forma compleja, imbricada y en algunos imposible de distinguir en cuanto a qué o quiénes lideran determinados proyectos, pues se trata justamente de trabajos orientados en torno a una misión común como Universidad en su conjunto. Tenemos que volver a insistir en la densidad de la historia de la Universidad en tanto se trenza con todos los ámbitos de la historia de nuestro país, marcando hitos que aún deben ser fijados, produciendo materiales que están dispersos y diseminados, incidiendo en las historias personales, sorprendiendo a quien entra a la Casa de Chile, como señala un documento compilado en el volumen de ensayos de esta edición especial de nuestros Anales, con sus vericuetos y recodos. Quizás, como en todo orden de cosas y apelando a la sabiduría popular, no hay mal que por bien no venga, y este sea el momento de recapitular, reinventar, crear y construir un nuevo gran relato para nuestra Universidad y para nuestro país.

Nota: En la transcripción de los documentos se ha respetado la grafía, organización y sistema de puntuación de los textos, así como su ortografía, como respeto al valor de su momento histórico. 